\title{
Philosophy of design, science of design, engineering (of) design: what is your choice?
}

\author{
Yoram Reich • Eswaran Subrahmanian
}

Published online: 14 September 2013

(C) Springer-Verlag London 2013

Designing is a fundamental human activity. We use it to solve our problems, reach beyond us to unknown worlds outside our galaxy and inside the atoms; we do designing to create our future for better or worse. With designing having such importance, it is critical that we understand what designing is and how can we improve it in our lives. It is a practical quest; not just for the sake of knowing about designing.

How is this understanding possible? It used to be that humans relied on beliefs, religion and faith to make sense of the world. At certain times the ideas underlying these beliefs or religions got encrypted in texts such as the Vedas or the Bible, dating before $1000 \mathrm{BC}$, which are said to be directly revealed from their divine sources, hence representing true knowledge about the world. These texts became sources for further study and interpretation through critical examination. This practice of questioning fundamental beliefs and answering important questions about anything around us, transformed into philosophy, a term attributed to Pythagoras. The practice of philosophy through dialectics, logical arguments, or critical thinking, became a cornerstone of western civilization as an approach to decipher the essence or even the truth about important questions. Philosophy seems a very appropriate approach to study designing as it tries to answer

\author{
Y. Reich $(\bowtie)$ \\ Tel Aviv University, Tel Aviv, Israel \\ e-mail: yoram@eng.tau.ac.il \\ E. Subrahmanian \\ Carnegie Mellon University, Pittsburgh, PA, USA \\ e-mail: sub@cmu.edu \\ E. Subrahmanian \\ NIST, Gaithersburg, MD, USA
}

fundamental questions about the world and us such as what is beauty (aesthetics), how do we distinguish between good or bad (ethics), or what is human purpose in inhabiting earth (metaphysics). These and other fundamental questions are essential to designing: we design artifacts for some purpose and judge them based on their perceived quality or beauty. But the practice of philosophy is imperfect. Simply consider the use of dialogues, a fundamental tool in philosophy, in studying important problems in physics by Galileo in his last book "Two New Sciences" (1638). Through dialogue, but without understanding the true physics, Galileo makes critical errors in his analysis of beam ultimate strength under bending.

So if in order to properly practice science, we need to experiment with the world beyond merely thinking about it, as Galileo did in some of his other studies, e.g., astronomy, we need another form of finding knowledge about the world-science. And although Galileo did not specify the scientific method, he is often considered as its originatorsystematic observation of nature and the formulation of laws with mathematics (Galileo 1623):

Philosophy [i.e. physics] is written in this grand book - I mean the universe — which stands continually open to our gaze, but it cannot be understood unless one first learns to comprehend the language and interpret the characters in which it is written. It is written in the language of mathematics, and its characters are triangles, circles, and other geometrical figures, without which it is humanly impossible to understand a single word of it; without these, one is wandering around in a dark labyrinth.

In the course of the Renaissance, through scholars such as Galileo, science replaced religion as a source of knowledge about the world. The scientific method-the way to do 
good science-perfected itself into an empirical inquiry, based on measurable data that leads to supporting or falsifying hypotheses about the world. In the last century, we have come to be obsessed with science. We adore science for its achievements from the nano to the scale of the universe. Given the increased complexity of our world, a by-product of the scientific revolution and the technology associated with it, we crave for order and simplicity and find ourselves in an increased addiction to science. Due to science, we know more about things around us but much less, and no more than before, about how to make sure that our knowledge is used towards good objectives, that is, we made much progress in our scientific knowledge but much less about the philosophical implications of using technology towards socially desirable goals. Achievements in science color all our existence with the desire to turn everything into science or name it "scientific," to claim legitimacy as if naming it so, would solve all problems.

Most readers would recognize the above path as the common story about the history of knowledge and its sources. However, as any other story, it can be told in a completely different way.

We can start by stating that religions are ingeniously designed products, having withstood almost intact for millennia (Reich 2010a). They are sources of knowledge for many people even today and they serve fundamental needs of people because they have been designed with astounding understanding of human nature. ${ }^{1}$ Consequently, if any of us finds insight in religions, it is due to designing that this outcome is afforded. To be precise, the outcome is due to the engineering of religions-their designing, implementation and adaptation to changing social environments through the design of institutions. This insight is not as important to our case as we did not imagine resorting to religion to understand designing so let us continue: what about philosophy as an approach to understand designing?

Philosophy could address important questions such as what is a function or property of an object. Let us recollect the way philosophy reaches conclusions. It is done by arguments, logic, or persuasion. Consider trying to define an object in metaphysics. As an example, we take the definition of the Internet network. We remove a server and it is a network, remove another and it is still a network. Finally, we remove the last server and there is no network whatsoever. At which point, in the process we have no Internet network and what do we have then? We have just designed a modern version of Sorites paradox which we cannot resolve. But the point on designing is much deeper. Philosophical practice involves dialect, dialogues, and determining the result of dialogue by judges or consensus. Philosophical practice is about designing to create stories,

$\overline{1}$ This is true whether the designer is god or a human. arguments, and other logical or rhetorical structures for delivering messages whose logical status are determined by people. A good philosopher would be an ingenious designer who understands the context in which he operates, his audience, who would then exercise the right balance of logos, pathos, and ethos, to convince the audience with his position. Actually, a good philosopher is a practicing engineer, who can design and implement his designs. ${ }^{2}$ So do we need a philosophy of design or an engineering of design?

All sources of knowledge thus far involve engineering (designing and implementation), but what about science? The answer will become clear once we start with Galileo. His first book, The Little Balance (1586), dealt with his design of a hydrostatic balance. He studied and in 1588 became an instructor of disegno-an early term for the word design. But perhaps the pick of his engineering related to his scientific activities materialized in his designs of various telescopes that let him extend his sight to conduct his astronomical inquiries and discover new knowledge. So while Galileo is thought to be an astronomer, mathematician, physicist, and a philosopher, he was really an engineer who got interested in all those fields through his work in solving practical problems (Valleriani 2010). Since the goal was solving practical problems, Galileo employed in his scientific inquiries any method necessary to create new knowledge: observations, induction or deduction. As engineers, we know that there is really no single method to do science (Konda et al. 1992; Feyerabend 2011), science can be designed to fit its objectives (Reich 2013), and there is no single way better than others to design such science or for that matter, any product (Reich 2010b); it is all a matter of what works.

Furthermore, since the beginning of science and even more so today, science has progressed through the engineering of tools that extend human sensing capabilities into the unknown. The unknown has been related to nature but also to the artifacts created by engineers. Technologies and solutions to problems developed by engineers became the subject of study for scientists (Petroski 2010).

But probing the unknown requires something else; it requires inventing new concepts. The failure of Galileo to find the ultimate strength of beams in bending cannot be attributed only to his exclusively using thought experiments when studying this subject. In this case, his failure was due to his limited language for describing beam internal stresses. He failed to invent the concept of the neutral axis and he did not recognize the triangular shape of internal stresses in bending. Galileo success and failure could both be attributed to the success or failure of his

\footnotetext{
${ }^{2}$ This is in line with some contemporary thinking in philosophy as a constructive activity (e.g., Floridi 2006).
} 
engineering ingenuity. The same holds for contemporary science that involves the designing and implementing of new concepts, tools and the knowledge about them (Hatchuel et al. 2013).

What is the upshot of the previous analysis? Should we be surprised that engineering turned out to be so fundamental to all knowledge seeking and forming activities? We think not. Children learn about stable and unstable structures by experimenting or designing and executing an experiment-building the tallest tower I can. More recent accounts of child development point to the creation of theories about the world by children in their efforts to deal with the physical and social worlds (Gopnick and Meltzoff 1996). So engineering is pervasive in humans. It is the most basic form of engaging with the world for the purpose of gaining knowledge about it for survival. Engineering is central to all other means of creating knowledge, including philosophy or science. It thus forms the most basic approach for studying to better know about anything in the world, including designing or engineering itself.

How then should we study design? Through a science of design? through philosophy of design? Or by engineering (of) design that subsumes all? If this idea sounds weird it is because we are not accustomed to think of engineering as a way of studying nature and the artificial. But carefully considered, engineering uses all the skills engineers developed throughout history to advance science, technology, and society. Shouldn't we use our own skills and methods to study what we do?

\section{References}

Feyerabend P (2011) The tyranny of science, English edn. Polity Press, Cambridge

Floridi L (2006) Philosophy of information. Oxford University Press, Oxford

Galileo G (1586) The little balance

Galileo G (1623) The assayer

Galileo G (1638) Two new sciences

Gopnick A, Meltzoff AN (1996) Words, thoughts, and theories. MIT Press, Cambridge

Hatchuel A, Reich Y, Le Masson P, Weil B, Kazakci A (2013) Beyond models and decisions: situating design through generative functions. In: Proceedings of the international conference on engineering design (ICED '13), Seoul, South Korea

Konda S, Monarch I, Sargent P, Subrahmanian E (1992) Shared memory in design: a unifying theme for research and practice. Res Eng Des 4(1):23-42

Petroski H (2010) The essential engineer: why science alone will not solve our global problems. Knopf, New York

Reich Y (2010a) Video of the talk given at the Alta Scuola Politecnica 8th Cycle Spring School, Belgirate, Italy. http:// www.youtube.com/watch?v=lr3NEJZHyOA

Reich Y (2010b) Editorial: My method is better! Res Eng Des 21(3):137-142

Reich Y (2013) Editorial: Designing science. Res Eng Des 24(3):215-218

Valleriani M (2010) Galileo engineer. Boston studies in the philosophy and history of science, book 269. Springer, New York 